\title{
Special issue dedicated to Former Editor-in-Chief Raphael T. Haftka
}

\author{
Nam H. Kim ${ }^{1} \cdot$ Nestor V. Queipo ${ }^{2}$. Felipe A. C. Viana ${ }^{3} \cdot$ Palaniappan Ramu $^{4} \cdot$ Erdem Acar $^{5} \cdot$ Helder C. Rodrigues $^{6}$. \\ Gengdong Cheng ${ }^{7} \cdot$ Ming Zhou $^{8}$
}

Published online: 30 October 2021

(c) The Author(s), under exclusive licence to Springer-Verlag GmbH Germany, part of Springer Nature 2021

This special issue is a collective effort from the Guest Editors and contributors to pay tribute to Professor Raphael "Rafi" T. Haftka, Former Editor-in-Chief of the Structural and Multidisciplinary Optimization Journal, who passed away in August 2020. As the editorial team mourned Rafi's passing, they collectively decided to organize a special issue to honor him.

Professor Raphael Haftka led the Structural and Multidisciplinary Optimization Journal as Editor-in-Chief since 2015 until he left us on August 16, 2020. Beyond his tremendous impact on our Journal and as a researcher during his remarkable 50 -year career, he will be remembered by many as a dear friend, mentor, and role model who stood out with wisdom, kindness, humility, generosity, and selfless service. $\mathrm{He}$ is also known for his universal silver lining perspective of an eternal optimist, with a distinct twist of Haftka style sense of humor.

Professor Haftka was born on February 22, 1944, in TelAviv, Israel. His professional journey started as an aerodynamicist at the Israeli Aircraft Industries from 1965 to 1968. From 1973 to 1975, he was a senior lecturer at TechnionIsrael Institute of Technology, after postdoctoral research fellowships at NASA and other US organizations. His career moved to the USA when he became an Assistant Professor at the Illinois Institute of Technology in 1975. Subsequently, he

Nam H. Kim

nkim@ufl.edu

University of Florida, Gainesville, FL, USA

Brunel Energy Inc., Houston, TX, USA

3 University of Central Florida, Orlando, FL, USA

4 Indian Institute of Technology Madras, Chennai, India

5 TOBB University of Economics and Technology, Ankara, Turkey

6 Universidade Técnica de Lisboa, Lisboa, Portugal

7 Dalian University of Technology, Dalian, China

8 Altair Engineering, Irvine, CA, USA held the positions as Professor/Christopher Kraft Professor at Virginia Tech from 1981 to 1994, and Professor/Distinguished Professor at the University of Florida from 1995 until retirement in 2019.

During his tenure as Editor-in-Chief, Professor Haftka significantly advanced the legacy of our founding editor Professor George Rozvany, doubling the journal's publishing volume and further strengthening its scientific impact. In particular, he made it a top priority for the journal to focus on its readers, emphasizing in his own words: “(a) Publish papers that are of interest; (b) Publish papers that are not unnecessarily difficult to read; (c) Publish papers with results that are easy to replicate". Two years ago, he introduced a new policy, making "Replication of Results" a mandatory section for all SMO publications. He also further strengthened our unique voluntary editor system invented by the founding editor George Rozvany. Now handling editors are credited by name in the publications. Another equally important aspect Rafi emphasized was fairness and equal opportunity for every contributing author. He constantly reminded our team of around 40 review editors of the importance of avoiding bias and the appearance of bias. All these efforts have been highly appreciated by authors, editors, and readers.

Professor Haftka's contributions to our research field are immeasurable-some important statistics: 330 journal papers, 530 conference proceedings papers, 12 book chapters, and 2 textbooks, and over 34,000 Google citations. His major research impacts include early pioneering contributions to approximation concepts including the far-reaching convex/conservative approximation; landmark papers on sensitivity analysis; leadership in creating/promoting MDO, surrogate modeling, and non-deterministic methods. The papers in this special issue are related to Rafi's recent research contributions, which include uncertainty quantification and reduction, reliability-based optimization, design under uncertainty, surrogate modeling and optimization, aircraft structural design, buckling design, and multidisciplinary optimization. 
Beyond his remarkable contributions as a researcher, Professor Haftka was also a key influencer within his research community. He was among the founders of ISSMO (International Society of Structural and Multidisciplinary Optimization) in 1991 and served as ISSMO's second president between 1995 and 1999. He has received many distinctions throughout his career, including Virginia Tech Alumni Award for Excellence in Research, AIAA Fellow, AIAA Multidisciplinary Design Optimization Award.

Another unique trademark of Professor Haftka's career is his broad outreach in collaborative research: he supervised $65 \mathrm{Ph}$.D. students, cooperated with colleagues worldwide, and was especially fond of nurturing aspiring young researchers. He co-authored papers with over 180 peers, excluding his students.

To honor Rafi's foundational research contributions and to recognize his passion for mentoring young researchers, the ISSMO community has introduced a new award in his name- 'Haftka Young Investigator Award' aimed at recognizing ISSMO researchers early in their careers for groundbreaking achievements and promising developments in the field of structural and multidisciplinary optimization. The award was inaugurated at WCSMO-14 held in June 2021 as a virtual conference (planned venue Boulder CO, USA). We are sure that the ISSMO community will carry on Rafi's legacy and continue to lead technology advancements that are increasingly important for combating climate change through enhancing energy efficiency of engineering products.

Guest Editors: Nam-Ho Kim, Nestor V. Queipo, Felipe A. C. Viana, Palaniappan Ramu, Erdem Acar, Helder C. Rodrigues, Gengdong Cheng, and Ming Zhou

Publisher's Note Springer Nature remains neutral with regard to jurisdictional claims in published maps and institutional affiliations. 